\title{
Young man with asthma and infertility
}

\author{
F.J. Gonzalez Barcala1, A. Pena1, L. Herrero1, A. Urtaza1, \\ M. García Domínguez¹, L. Valdes Cuadrado2
}

ABSTRACT: Young man with asthma and infertility. F.J. Gonzalez Barcala, A. Pena, L. Herrero, A. Urtaza, M. García Domínguez, L. Valdes Cuadrado.

Asthma and male infertility are common diseases that can occur in the same patient. In some cases they could have patho-physiological changes common to both diseases. Our patient was seen as a result of having an irritating cough with wheezing, mainly at night, for more than a month. Asthma was diagnosed, and he responded favourably to the treatment given. Upon being informed that he had been examined for infertility for 5 years, alpha-1 antitrypsin (AAT) levels were requested. These confirmed that he had a phenotype SZ AAT deficiency. These findings, together with some evidence published recently, suggested that there is a need to rule out AAT deficiency in males with asthma and infertility. Monaldi Arch Chest Dis 2009; 71: 4, 180-181.

Keywords: Alpha-1-antitrypsin deficiency, Asthma, Infertility.

1 Servicio de Neumologia, Hospital de Pontevedra,

2 Servicio de Neumología, Hospital Clinico Universitario de Santiago de Compostela, Spain.

Correspondence: Gonzalez Barcala, FJ, Servicio de Neumologia. Hospital de Pontevedra, C/Loureiro Crespo 2, 36002-Pontevedra, Spain;e-mail:fjgbarcala@telefonica.net

\section{Introduction}

Asthma is a highly prevalent disease that is estimated to affect 300 million people worldwide [1].

Infertility also has a high prevalence, with between $4 \%-17 \%$ of couples asking for medical assistance for this problem. Of these, the primary problem lies with the male in $20 \%$ of the cases, and with both partners in another $26 \%$ [2].

Although we are not aware of any studies that evaluate fertility in male asthmatics, the same fertility rate has been observed in women with this disease as in non-asthmatics [3].

The high prevalence of both conditions could determine the coincidence in the same patient; but in some cases it could be due to a pathophysiological mechanism common to both diseases.

A clinical presentation of bronchial hyper-reactivity and other signs and symptoms of asthma is common in patients with alpha-1-antitrypsin deficiency (AAT-D) [4]. Recent studies also seem to support the relationship between AAT-D and infertility [5].

We present the case of a male with asthma, in a fertility study, who is also diagnosed with AAT-D.

\section{Case report}

A 36 year-old male, who complained of an irritating cough for more than one month. He also mentioned occasional wheezing, mainly at night. Of interest in his medical history was the absence of any known allergies, the fact that he had never been a smoker, that he works as a janitor in a sports centre, and has no other illnesses.
Wheezing was heard in the chest examination, with no other noteworthy changes.

In the complementary examinations, the laboratory tests and $\operatorname{IgE}$ were normal and there were no abnormalities seen in the chest and paranasal sinuses $\mathrm{X}$-rays.

In the spirometry the $\mathrm{FVC}$ was $5790 \mathrm{ml}$ (103\%); FEV $4640 \mathrm{ml}(101 \%)$, PEF $11.23 \mathrm{~L} / \mathrm{sec}$ $(110 \%)$, and the bronchodilation test with beta-2 agonist was positive.

On reviewing his previous history it was observed that he had been examined for infertility over the past 5 years (ultrasonography shows left varicocele, sperm count shows oligozoospermia, the karyotype was $46, \mathrm{XY})$. In view of this finding, sweat chloride and AAT levels were requested. Sweat chloride was normal, a protein electrophoresis showed reduced alpha-1 globulin peak (figure 1); AAT levels were $48 \mathrm{mg} / \mathrm{dL}$, and the genetic study showed up a SZ phenotype.

Treatment was commenced with inhaled corticoids and beta- 2 agonists, the patient remaining asymptomatic, from a respiratory perspective, since then.

\section{Discussion}

The usual method of obtaining a diagnosis of AAT-D is by examining the respiratory symptoms, or by screening the families of other already known patients $[6,7]$. Even in patients with ZZ phenotype, who have not been exposed to particular environmental toxins, the lung function can be normal in the first 3 decades of life $[8,9]$. This fact, together with the non-specific symptoms causes delays in the diagnosis. In the 1990's, the 


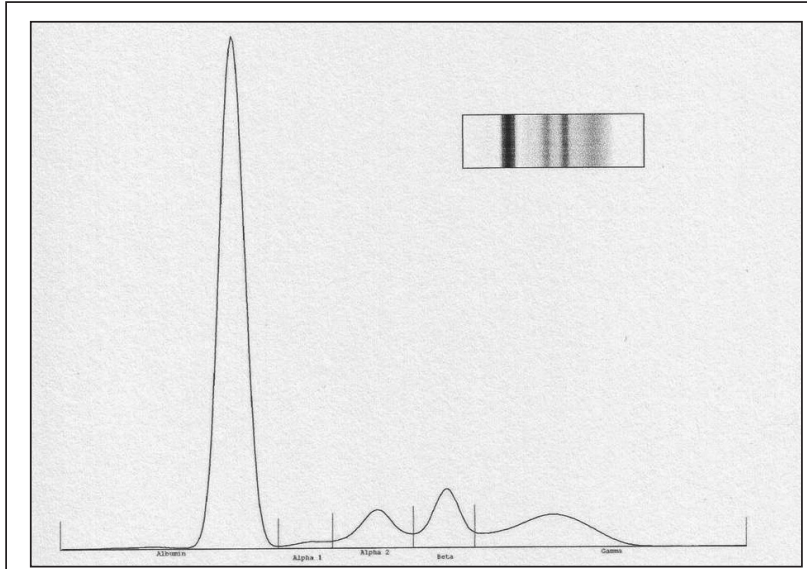

Fig. 1

mean time between the appearance of the first symptom and the diagnosis was 7.2 years, and $44 \%$ had consulted at least 3 doctors to reach a correct diagnosis [10].

In our patient, once cystic fibrosis seems to be reasonably excluded, the possibility of AAT-D was assessed.

The relationship between asthmatic symptoms and AAT-D is well known [11].

It is also known that seminal plasma contains AAT and other serpins [12]. This led to some research into the possible relationship between AAT-D and male infertility [5].

This is in agreement with evidence obtained from a recent publication, where it was reported that AAT-D could favour the deterioration of spermatozoids, with the resulting decrease in fertility [5].

The mechanisms involved could be associated with an increase in inflammatory activity, since it is known that there is a decrease in fertility in males with inflammatory diseases, although the patho-physiological processes are not well identified [13]. In AAT-D there is an imbalance produced between AAT and elastases, and the latter are an essential component in the regulation of inflammatory processes [14].

A concentration dependent effect of elastase over the decrease in spermatozoid activity, as well as the protective ability of AAT over this elastase effect, has also been observed [5].

Furthermore, other effects of inflammation have been demonstrated in animal models at testicular level as well as in the structure and function of the spermatozoids (increase in spermatocyte apoptosis, delay in the maturing of spermatozoids, inhibition of various functions of the Sertoli cell, a direct effect on the seminiferrous epithelium in LPS-induced inflammation) which led to lower fertility in males [15].
Knowledge of these facts, and the presence of infertility in an asthmatic male, should signal a possible underlying disorder, which could determine the association with the asthma.

In view of this case we consider that when faced with a patient with asthma and infertility the possibility of an AAT-D must be investigated.

\section{References}

1. http://www.ginasthma.com. Update december 2008.

2. Bhasin S. Approach to the infertile man. J Clin Endocrinol Metab 2007; 92: 1995-2004.

3. Tata LJ, Hubbard RB, McKeever TM, et al. Fertility rates in women with asthma, eczema, and hay fever: a general population-based cohort study. Am J Epidemiol 2007; 165: 1023-30.

4. van Veen IH, ten Brinke A, van der Linden AC, Rabe $\mathrm{KF}$, Bel EH. Deficient alpha-1-antitrypsin phenotypes and persistent airflow limitation in severe asthma. Respir Med 2006; 100: 1534-9.

5. Leßig J, Arnhold J, Glander HJ. alpha-antitrypsin prevents polymorphonuclear leucocyte-elastase effects on spermatozoa quality. Int J Androl 2009 Mar 5. [Epub ahead of print].

6. Needham M, Stockley RA. Alpha 1-antitrypsin deficiency. 3: Clinical manifestations and natural history. Thorax 2004; 59: 441-5.

7. Hogarth DK, Rachelefsky G. Screening and familial testing of patients for alpha 1-antitrypsin deficiency. Chest 2008; 133: 981-8.

8. Piitulainen E, Sveger T. Respiratory symptoms and lung function in young adults with severe alpha(1)-antitrypsin deficiency (PiZZ). Thorax 2002; 57: 705-8.

9. Piitulainen E, Carlson J, Ohlsson K, Sveger T. Alpha1antitrypsin deficiency in 26-year-old subjects: lung, liver, and protease/protease inhibitor studies. Chest 2005; 128: $2076-81$.

10. Stoller JK, Smith P, Yang P, Spray J. Physical and social impact of alpha 1-antitrypsin deficiency: results of a survey. Cleve Clin J Med 1994; 61: 461-7

11. Eden E, Mitchell D, Mehlman B, et al. Atopy, asthma, and emphysema in patients with severe alpha-1-antitrypysin deficiency. Am J Respir Crit Care Med 1997; 156: 68-74.

12. Pilch B, Mann M. Large-scale and high-confidence proteomic analysis of human seminal plasma. Genome Biol 2006; 7: R40.

13. Moretti E, Cosci I, Spreafico A, Serchi T, Cuppone AM, Collodel G. Semen characteristics and inflammatory mediators in infertile men with different clinical diagnoses. Int J Androl 2008 Aug 15. [Epub ahead of print].

14. Pham CT. Neutrophil serine proteases: specific regulators of inflammation. Nat Rev Immunol 2006; 6: 541-50.

15. Liew SH, Meachem SJ, Hedger MP. A stereological analysis of the response of spermatogenesis to an acute inflammatory episode in adult rats. J Androl 2007; 28: 176-85. 